\title{
Analysis of the genetic determinant for production of the peptide antibiotic nisin
}

\author{
H. M. DODD, ${ }^{*}$ N. HoRN and M. J. GaSSON \\ Department of Genetics and Microbiology, AFRC Institute of Food Research, Norwich Laboratory, Colney Lane, \\ Norwich-NR4 7UA, UK
}

(Received 21 August 1989; revised 12 November 1989; accepted 30 November 1989)

\begin{abstract}
The structural gene for the precursor of the peptide antibiotic nisin was isolated and characterized. As with other lanthionine-containing antibiotics, nisin is synthesized as a pre-propeptide which undergoes post-translational modification to generate the mature antibiotic. The sequence data obtained agreed with those of precursor nisin genes isolated by other workers from different Lactococcus lactis strains. Analysis of regions flanking the precursor nisin gene revealed the presence of a downstream open reading frame that may be involved in maturation of the precursor molecule. Nucleotide sequences characteristic of an IS element were located upstream of the nisin determinant. This element, termed IS904, is present in multiple copies in the genome of $L$. lactis. The nisin determinant of $\boldsymbol{L}$. lactis is a component of a large transmissible gene block that also encodes nisin resistance and sucrose-metabolizing genes. Gene probe experiments indicated that the nisin/sucrose gene block was located in the chromosome. Furthermore, the copy of IS904 identified adjacent to the precursor nisin gene lies at, or very close to, one end of this transmissible DNA segment and may play a role in mediating its transfer between strains.
\end{abstract}

\section{Introduction}

Recent interest in the antagonistic properties of lactic acid bacteria has led to the discovery of a wide range of antimicrobial agents with relatively broad-spectrum activities (Klaenhammer, 1988). The one established antimicrobial from Lactococcus that is widely used in the food industry is nisin. The ability of this antibiotic to inhibit sporulation of spoilage bacteria has led to its extensive use as a preservative, particularly for dairy and canned food products (Hurst, 1981). In addition, nisin inhibition of both Listeria monocytogenes (Benkerroum \& Sandine, 1988) and Clostridium botulinum (Tayler \& Somers, 1985) suggests a potentially wider role in future protection of the food supply.

Nisin is a member of a unique group of small ribosomally synthesized peptide antibiotics which includes subtilin (Gross \& Kiltz, 1973), epidermin (Allgaier et al., 1986) and gallidermin (Kellner et al., 1988). These antibiotics have in common a high proportion of the sulphur-containing amino acids lanthionine and $\beta$ -

Abbreviations: IR, inverted repeat; ORF, open reading frame; PCR, polymerase chain reaction.

The nucleotide sequence data reported in this paper have been submitted to GenBank and have been assigned the accession numbers M27276 and M27277. methyllanthionine. The most prominent structural feature of the molecules is the lanthionine rings formed by these atypical residues (Gross \& Morell; Fig. $1 a$ ) and the term lantibiotic has been proposed for these related antibiotics. The presence of non-coded amino acids indicates that enzymic modification of a primary translation product occurs to generate the mature lantibiotic. Reactions between appropriately located serine and cysteine or threonine and cysteine residues in the precursor molecule have been proposed (Ingram, 1970) which would generate the lanthionine rings of the mature antibiotic. This sequence of events was confirmed by the cloning and nucleotide sequence analysis of a gene for the precursor of epidermin (Schnell et al., 1988). Genes for the precursors of other lantibiotics have recently been cloned and sequenced (Banerjee \& Hansen, 1988; Buchman et al., 1988; Kaletta \& Entian, 1989; Schnell et al., 1989) and in each case confirmation of this mode of synthesis was found. However, the mechanism of lantibiotic biosynthesis from the primary translation product has not been elucidated nor have the genes involved been identified.

The genetic determinant for nisin production is one component of a curable and transmissible gene block that also encodes nisin resistance and sucrose-metabolizing genes (Gasson, 1984; Steele \& McKay, 1986). 

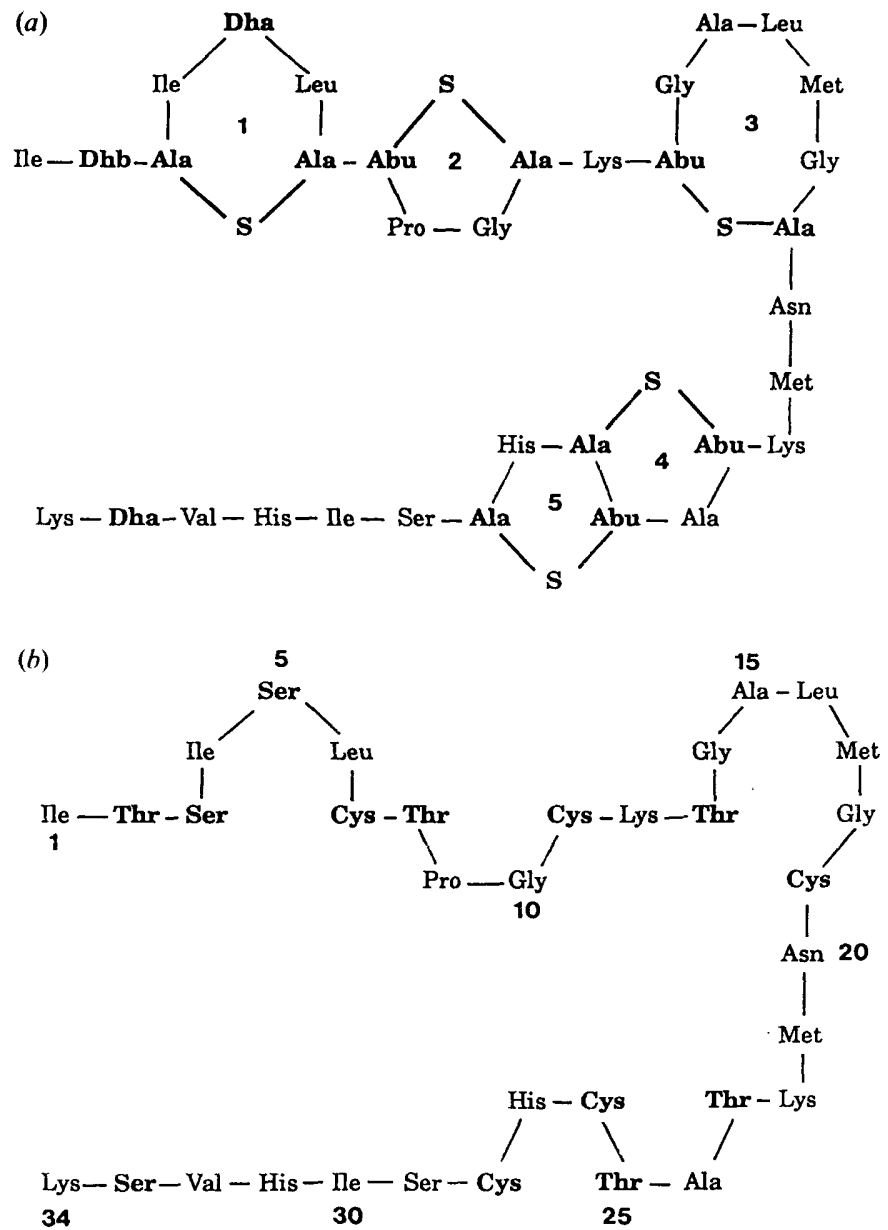

Fig. 1. (a) Structure of nisin (from Gross \& Morell, 1971). The atypical amino acids, in bold letters, are dehydroalanine, Dha; dedhydrobutyrine, Dhb; aminobutyrate, Abu; lanthionine, Ala-S-Ala; and $\beta$ methyllanthionine, Abu-S-Ala. (b) Predicted amino acid sequence of precursor nisin. Amino acids involved in modification reactions are in bold letters.

These properties have led to speculation that nisin production is determined by a conjugally transmissible plasmid (Kozak et al., 1974; Fuchs et al., 1975; Leblanc et al., 1980; Gonzalez \& Kunka, 1985). Tsai \& Sandine (1987) reported the conjugal transfer of nisin determinants from Lactococcus lactis to Leuconostoc dextericum and this was correlated with acquisition of a $28 \mathrm{~kb}$ plasmid. However, to date, the physical isolation of plasmid DNA which is able to transform $L$. lactis strains into nisin producers has not been demonstrated.

Here the cloning and nucleotide sequence analysis of the nisin structural gene and the adjacent regions of DNA from a nisin-producing transconjugant of Lactococcus lactis MG1614 is reported. Buchman et al. (1988) and Kaletta \& Entian (1989) have independently cloned and analysed a similar region from different nisinproducing culture collection strains of $L$. lactis and these results are compared.

\section{Methods}

Bacterial strains and plasmids. Lactococcus lactis FI5876 was constructed by conjugal transfer of the nisin determinants from NCFB 894 (Gasson, 1984) to the plasmid-free strain MG1614 (Gasson, 1983). Selection was made for transconjugants able to metabolize sucrose, as described by Gasson (1984) FI6016 is MG1614 carrying plasmid pFI172 (see below).

Escherichia coli P2392 and LE392 were the host strains used to isolate and propagate $\lambda E M B L 3$ recombinants (Maniatis et al., 1982). E. coli MC1022 [araDI39 $\Delta($ ara, leu)7697 lacZAM15 galU galK rspL; Casadaban \& Cohen, 1980] was the host strain for construction of plasmid pF1172. This plasmid, derived from the broad-host-range $L$. lactis vector pTG262 (Shearman et al., 1989), contains the cloned precursor nisin gene (Fig. $2 b$ ).

Microbiological techniques. L. lactis strains were propagated at $30^{\circ} \mathrm{C}$ in M17 medium (Terzaghi \& Sandine, 1975) supplemented with $0.5 \%$ (w/v) glucose instead of lactose. E. coli strains were propagated at $37^{\circ} \mathrm{C}$ in $L$ broth (Lennox, 1955).

Nisin production was detected by the plate diffusion assay (Tramer \& Fowler, 1964), using as an indicator the nisin-sensitive strain MG1614 (Gasson, 1983).

Nisin resistance was determined by streaking $L$. lactis NCFB 894 (a nisin-producing strain) across the surface of an M17 agar plate containing $0.5 \%(\mathrm{w} / \mathrm{v})$ glucose. After overnight growth $\left(\right.$ at $\left.30^{\circ} \mathrm{C}\right)$ the plate was inverted over chloroform for $10 \mathrm{~min}$ to kill the cells. Strains to be tested were streaked across the chloroform-treated NCFB 894 streak and the plates reincubated. Nisin sensitivity was indicated when growth of the test strain ceased just before the intersection of the streaks, in the area in which nisin produced by NCFB 894 had diffused into the surrounding agar. Nisin-resistant strains grew throughout the length of the whole streak.

For screening and selection of strains able to metabolize sucrose, bromocresol purple indicator (BCP) agar (McKay et al., 1972) was used, with sucrose $(0.5 \%, \mathrm{w} / \mathrm{v})$ replacing lactose.

Transformation. Recombinant plasmids were recovered by transformation of either E. coli MC1022 by the method of Cohen et al. (1972) with the modification of Humphreys et al. (1979) or L. lactis MG1614 by electroporation using a Gene Pulser apparatus (Bio-Rad) as described by Shearman et al. (1989).

Molecular techniques. Plasmid DNA was isolated by the SDSalkaline lysis method and purified by caesium chloride/ethidium bromide gradient centrifugation (Maniatis et al., 1982). Total genomic DNA from $L$. lactis FI5876 was prepared according to the method of Lewington $e t$ al. (1987). The plate lysate method for rapid small-scale isolation of bacteriophage $\lambda$ DNA (Maniatis et al., 1982) was used for isolation of recombinant $\lambda$ EMBL3 DNA.

Restriction enzymes and other DNA-modifying enzymes used were obtained from Pharmacia, BRL or Amersham and used according to the supplier's recommendations. DNA ligations and agarose gel electrophoresis were done by standard procedures (Maniatis et al., 1982).

Genomic library construction and recombinant detection. Total DNA isolated from L. lactis FI5876 was partially digested with Sau3A and fragments were purified by sucrose density centrifugation. A genomic 
library of $10^{6}$ recombinants was generated by their ligation with $\lambda E M B L 3$ arms (according to the cloning manual supplied by Stratagene, USA).

Two different approaches involving DNA probes were used to screen the library for the precursor nisin gene. A 123 bp DNA fragment encoding the predicted 34 amino acids of precursor nisin (see Fig. $1 b$ ) was synthesized, the nucleotide sequence being based on $E$. coli codon usage. The fragment was assembled from two 70-nucleotide oligomers which were designed such that the 17 bases at the $3^{\prime}$ end of each molecule were complementary. As a result of annealing the two strands, a 17 bp overlap was generated. Synthesis from the two free $3^{\prime}-\mathrm{OH}$ groups, using Klenow fragment of DNA polymerase I, filled in the single-stranded regions, resulting in a double-stranded $123 \mathrm{bp} \mathrm{BamHI/}$ EcoRI fragment (enzyme sites were included in the initial design of the oligomers). The fragment was cloned into the bacteriophage vector M13 and its sequence confirmed by the dideoxy chain-termination method of Sanger et al. (1980).

An alternative probe involved the synthesis of a 17-nucleotide mixed oligomer that corresponded to a region of low codon degeneracy within the predicted precursor nisin sequence. For amino acids 17 to 22 (Fig. $1 b$ ) a mixture of 16 different 17 -mers contained all the possible codons that might be located in this stretch of the gene [ATGGG(A/C/G/T)TG(C/G)AA(T/C)ATGAA].

The mixed oligomer was end-labelled using $\mathrm{T} 4$ polynucleotide kinase (Maniatis et al., 1982) and the 123 bp fragment was labelled using the multiprime DNA labelling system (Amersham, UK). Both probes were used to screen the unamplified library. Because of the possibly limited homology between the probes and $\lambda E M B L 3$ recombinant DNA in plaque hybridizations, conditions of low stringency were chosen. Hybridizations were carried out in $3 \times$ SSC $(1 \times$ SSC is $0.15 \mathrm{M}$ $\mathrm{NaCl} / 0.015$ M-trisodium citrate, $\mathrm{pH} 7 \cdot 0), 0 \cdot 5 \%(\mathrm{w} / \mathrm{v}) \mathrm{SDS}, 0.5 \%(\mathrm{w} / \mathrm{v})$ skimmed milk powder, $0.01 \%(\mathrm{w} / \mathrm{v})$ Ficoll, $0.01 \%(\mathrm{w} / \mathrm{v})$ polyvinylpyrrolidone, and $0.5 \mathrm{mg}$ salmon sperm DNA ml $\mathrm{m}^{-1}$. Hybridization and wash temperatures were $48{ }^{\circ} \mathrm{C}$ for the 123 bp probe and $30^{\circ} \mathrm{C}$ rising to $33^{\circ} \mathrm{C}$ for the end-labelled mixed oligomer

Nucleotide sequence analysis. This was performed by the dideoxy chain-termination method (Sanger et al., 1980) using the modified T7 polymerase 'Sequenase' system (United States Biochemical Corp.) according to the supplier's recommendations. The 17-nucleotide mixed oligomer (described above) was initially used in 10-fold excess as a primer in order to target the precursor nisin sequence. Further primers were synthesized from identified sequences as they became available. The sequences of both strands were determined (shown in Fig. 3) and the data compiled using the DNA analysis programs of the University of Wisconsin Genetics Computer Group (UWGCG; version 5.3, 1988).

The synthetic primers and probes used in this work were made on an Applied Biosystems DNA synthesiser (model 381A). The phosporamidite method of oligonucleotide synthesis was followed according to the manufacturer's instructions and using chemicals and columns supplied by them.

Polymerase chain reaction (PCR). The reaction mix consisted of : $25 \mu \mathrm{l}$ $4 \times$ reaction buffer $(40 \mathrm{mM}-\mathrm{Tris} / \mathrm{HCl} \mathrm{pH} 8.3 ; 200 \mathrm{mM}-\mathrm{KCl} ; 6 \mathrm{mM}-$ $\mathrm{MgCl}_{2} ; 0.04 \%$ gelatin; $800 \mu \mathrm{M}$-dATP, dCTP and dTTP; $200 \mathrm{mM}-$ dGTP; $600 \mathrm{mM}$-dc ${ }^{7} \mathrm{GTP}$ ); $20 \mathrm{pmol}$ of each primer; $1.0 \mu 110 \%$ Triton $\mathrm{X}-100 ; 3$ units Taq DNA polymerase; $1 \mu \mathrm{g}$ pFI172 DNA. The final volume of $100 \mu \mathrm{l}$ was overlaid with $100 \mu \mathrm{l}$ sterile mineral oil. Reactions were carried out in a Techne Programmable Dri-Block. Primers corresponding to two 17-nucleotide regions within the precursor nisin gene were synthesized. For the specific amplification of DNA sequences lying between these primers (Fig. 3, coordinates 2242 to 2426) the programmable Dri-Block was run for 25 cycles at $90{ }^{\circ} \mathrm{C}$ for $2 \mathrm{~min}, 55^{\circ} \mathrm{C}$ for $2.5 \mathrm{~min}$ and $70^{\circ} \mathrm{C}$ for $2.5 \mathrm{~min}$. The amplified fragment was isolated from a gel and labelled as described above.

\section{Results and Discussion}

\section{Identification and mapping of precursor nisin clones}

A genomic library containing partial Sau3A fragments of $L$. lactis FI5876 was constructed in $\lambda$ EMBL3. The unamplified library was screened for precursor nisin sequences using two alternative probes (see Methods). Under the conditions used, a mixed 17-nucleotide oligomer failed to give a sufficiently strong signal to distinguish between homologous and non-specific hybridization. A 123 bp probe, based on a synthetic gene for precursor nisin, proved more successful and displayed weak homology with approximately $1 \%$ of the $\lambda$ EMBL3 clones. DNA from six plaques which gave positive signals was isolated and analysed with restriction enzymes. All the DNAs had inserts which varied in size, although digestion with $S a l$ (which cuts at the junctions between the $\lambda E M B L 3$ arms and the inserted $L$. lactis DNA) generated some fragments of common size, indicating that a similar region of the $L$. lactis genome was present in the six clones (see Fig. $2 a$ ). In Southern transfer hybridization of these digestion patterns, a single Sall fragment displayed homology with the $123 \mathrm{bp}$ probe (data not shown). Homology lay within a $4.4 \mathrm{~kb}$ fragment in clones $1,2,3$ and 5 , a $5 \cdot 1 \mathrm{~kb}$ fragment in clone 4 and a $5.5 \mathrm{~kb}$ fragment in clone 6 . From restriction enzyme analysis it was established that all these fragments were defined by the same Sall site within the L. lactis DNA, near the right-hand end of the different cloned inserts, and by the SalI site at the junction with the AEMBL3 arms (Fig. 2a). The fact that four out of six of these fragments were identical in size (clones 1, 2, 3 and 5) indicated that one end of all these clones was generated by digestion at the same Sau3A site in the original partial digestion of $L$. lactis FI5876 chromosomal DNA. The Sau3A sites defining the end-points of clones 4 and 6 were located very near to those of the other clones $(0.4 \mathrm{~kb}$ and $1 \cdot 1 \mathrm{~kb}$ respectively; Fig. $2 a)$.

Digestions with Bg/II and HincII and Southern transfer hybridizations of the restriction patterns generated confirmed the mapping of the six clones as shown in Fig. 2. Furthermore, from these data, it was possible to narrow down the region of homology with the precursor nisin probe to sequences lying within a $\mathrm{HincII} / \mathrm{Sa} / \mathrm{I}$ fragment at the extreme right-hand end of all six clones. It is possible that insertion of sequences lying to the right of those cloned in $\lambda$ EMBL3 recombinant 6 (Fig. 2a) are detrimental to phage growth. The signal denoting homology with the synthetic probe was weak in plaque hybridizations due to the incomplete homology of this probe with the precursor nisin gene sequence $(72 \%$; see below). Screening the library with sequences from the cloned fragment, which would display $100 \%$ homology, 


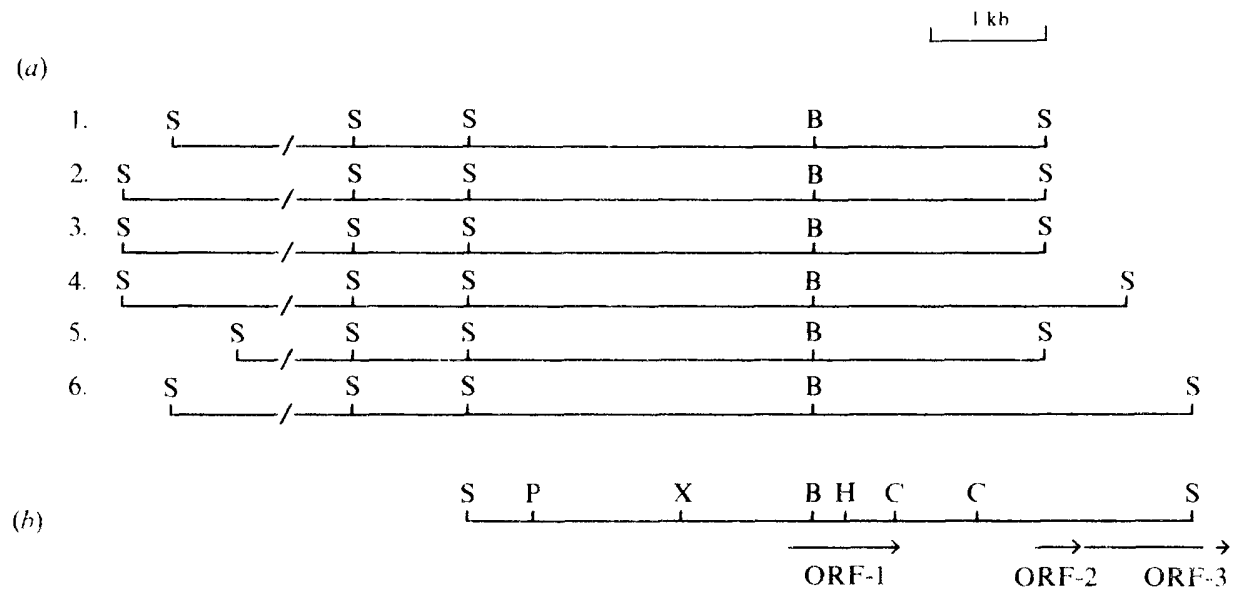

Fig. 2 Restriction maps of cloned L. lactis DNA. Restriction en zyme sites indicated are: S, SalI; P, P: $u I I: X, X b a I ; B, B g I I I ; H$; HindIII; C, HincII. (a) AEMBL3 recombinants containing precursor nisin gene The order of restriction enzyme sites in the left-hand $S a l$ fragment has not been established, as indicated by the broken line. The $S a l$ sites at the two ends originate from sequences in the AEMBL 3 arms, the end-point of the inserted DNA being defined by Sau 3 A sites (see Methods). (b) pFI172, comprising the $5 \cdot 5 \mathrm{~kb}$ SalI fragment originating from $\lambda \mathrm{EMBL} 3$ clone 6 inserted in vector $\mathrm{pTG} 262$. The location and orientation of the open reading frames (ORFs) identified from the nucleotide sequence are indicated under the map

has identified additional recombinants from outside the region already cloned. These are being analysed.

\section{Precursor nisin gene - nucleotide sequence analysis}

The $5.5 \mathrm{~kb}$ Sall fragment from $\lambda \mathrm{EMBL} 3$ recombinant 6 was cloned into pTG262 to generate pFI172 (Fig. 2) and subjected to nucleotide sequence determination. A $2.5 \mathrm{~kb}$ sequence identified from within this fragment is shown in Fig. 3. Three open reading frames (ORFs) were located in this region (Fig. 2b). The 171 bp ORF-2 (Fig. 3 , coordinates 2215 to 2385 ) was identified as the gene for precursor nisin. It encodes a 57 -amino-acid polypeptide of which the $34 \mathrm{C}$-terminal residues correspond precisely to those predicted for precursor nisin. Serine, threonine and cysteine residues were located at the appropriate positions within the structural gene so as to generate the lanthionine, $\beta$-methyllanthionine and dehydro-residues present in mature nisin (Fig. 1). The $\mathrm{N}$-terminal 23 amino acids represent a leader sequence involved in export of nisin through the cell wall, cleavage occurring between arginine and isoleucine residues of the precursor molecule during this process. Buchman et al. (1988) established that precursor nisin is synthesized as a prepropeptide which undergoes post-translational modification. The conclusions drawn from our independent results and those of Kaletta \& Entian (1989) support this mechanism for nisin biosynthesis.

A comparison of sequences obtained here with those published previously (Buchman et al., 1988; Kaletta \& Entian, 1989), indicated that the genes for precursor nisin were identical. Furthermore, the similarities between strains extended into the regions flanking this structural gene. The start of an ORF is located 108 bp downstream of the precursor nisin gene (coordinate 2496, Fig. 3). This partially sequenced potential coding region extends for at least $1 \mathrm{~kb}$ downstream (data not shown). Buchman et al. (1988) have presented the first $190 \mathrm{bp}$ of the equivalent ORF. In their strain, both this coding region and the intergenic sequence showed $100 \%$ homology with those obtained here. This identity between independently isolated L. lactis strains probably reflects the transmissible nature of this antibiotic determinant and may indicate the relatively recent dissemination of nisin biosynthesis genes.

\section{Expression of cloned L. lactis DNA}

Plasmid pFI172, carrying the cloned precursor nisin gene, was introduced into L. lactis MG1614 by electroporation to generate strain FI6016. When tested for expression of genes associated with the nisin/sucrose gene block, this strain did not produce active nisin. Plasmid-mediated traits in L. lactis strains are often spontaneously lost as a result of deletion (Gasson et al., 1987). Such deletion events do not appear to have affected the recombinant plasmids in this study. Plasmid pFI172 DNA isolated from both $E$. coli and L. lactis backgrounds had identical restriction enzyme profiles (data not shown), indicating that the precursor nisin gene was intact.

One obvious reason for the absence of nisin production by the cloned nisin structural gene is the lack of 
maturation enzymology in strain FI6016. Nucleotide sequence analysis of the cloned L. lactis DNA in pFI172 suggested that this plasmid is unlikely to encode complete genes for enzymes involved in modification of precursor nisin. There is no previous evidence to suggest that these genes are linked to the nisin structural gene and the possibility exists that this maturation function is genetically separate, perhaps fulfilling other functions in the cell. Assuming that the cloned nisin precursor gene is expressed by $L$. lactis carrying pFI172, its failure to produce nisin supports the likely genetic linkage of maturation genes and the nisin structural gene. Whilst expression of the pFI172-encoded nisin precursor gene in L. lactis has yet to be demonstrated in vivo, the inclusion of one terminus of the nisin/sucrose gene block (see later) proves the presence of all upstream regions likely to be involved in its transcription.

A potential hairpin loop is located in the small intergenic gap between ORFs 2 and 3 (Fig. 3). It is not followed by the run of Ts which characterizes rhoindependent terminators (Rosenberg \& Court, 1979) and the suggestion has been made that these inverted repeat sequences (IRs) represent a processing site for a large polycistronic message in which ORF-3 is transcribed by readthrough from the upstream precursor nisin gene (Buchman et al., 1988). From the $1 \mathrm{~kb}$ sequence determined to date no similarity has been found with sequences in the EMBL or GenBank databases to suggest a function for ORF-3. However, the potential linkage with the precursor nisin gene, at the level of transcription, may indicate that this downstream coding region is involved in the production of nisin.

The presence of determinants for nisin resistance and sucrose metabolism on pFH172 was tested. L. lactis FI6016 did not exhibit either of these genetically linked phenotypes. Other DNA fragments flanking the precursor nisin gene have been isolated and are being investigated for the presence of these genes together with those involved in the maturation of precursor nisin.

\section{IS904 - nucleotide sequence analysis}

On examination of nucleotide sequences upstream of the precursor nisin gene, a region was found which exhibited many of the hallmarks characteristic of IS elements. IRs of $39 \mathrm{bp}$ were found which would generate an element of 1241 up (Fig. 3) designated IS904 (registered with the Plasmid Reference Center Registry; Lederberg, 1987). The only ORF of significant length ( $>300 \mathrm{bp}$ ) within these IRs was ORF-1 (coordinates 625 to 1386; Fig. 3), which would encode a protein of 253 amino acids. When this sequence was compared with those in the databases, significant homology was found with the transposases of insertion sequences IS3 (1258 bp; Timmerman \& Tu,
$1985)$ and íS600 (1264 bp; Matsutani et al., 1987). These latter two elements are present in multiple copies in the genomes of the Gram-negative organisms E. coli and Shigeila dysenteriae, respectively. The $L$. lactis protein is smaller than those encoded by IS 3 and IS600, but the homology extends throughout the sequences $(47 \%$ homology with IS3 and $49 \%$ homology with IS600 when conservative changes are considered as matched; see Fig. 4). The $109 \mathrm{C}$-terminal amino acid sequence encoded by a similarly located ORF was presented in the results of Buchman et al. (1988). Only one difference at the amino acid level was noted between this latter sequence and the one presented here. This involved the substitution of a serine with a threonine residue (amino acid 202, Fig. 4). A conservative change of this type may not functionally alter the activity of the putative transposase and could be accomplished by a single point mutation at the nucleotide level.

Upstream of the coding region for the putative transposase of IS904, homology with IS 3 and IS600 is insignificant, but some similarity is again found at the ends of the elements. A second element (IS629), present in multipie copies, has been identified in $S$. dysenteriae. It is $1310 \mathrm{bp}$ in length, and is closely related to IS600 and thus to IS 904 and IS3. Nucleotide sequences for the ends of IS629 have been determined (Matsutani et al., 1987) and these, together with the IRs of IS600 and IS3, are compared with those of IS904 in Fig. 5. The two ends of all four elements terminate with the dinucleotide $5^{\prime}$-TG followed by a purine. Homology is most pronounced between IS904 and IS3, both of which are flanked by 39 $\mathrm{bp}$, imperfect IRs, containing 8 and 11 mis-matches respectively. The IRs of the two elements resident in $S$. dysenteriae are about $10 \mathrm{bp}$ shorter, but they contain an internal region made up of sequences common to all eight termini (Fig. 5). A second region within the longer IRs of IS904 is also present in IS3. These sequence homologies within the IRs might be expected, as these regions are specifically recognized by the transposases of the respective elements, which have also been shown to be related. Examination of IS904 sequences adjacent to the IRs revealed the presence of a $10 \mathrm{bp}$ direct repeat of the extreme end of IR-L. This truncated IR lies $44 \mathrm{bp}$ in from the left end of the element (Fig. 3; coordinates 229 to 238).

As a consequence of the process of transposition, the target site is usually duplicated and is present as directly repeated sequences flanking the newly inserted element. Both IS 3 and IS 600 generate a $3 \mathrm{bp}$ duplication of the target site upon transposition (Yoshioka et al., 1987; Timmerman \& Tu, 1985; Matsutani et al., 1987). The sequence TATT is found at either end of the IRs of IS904 (Fig. 3). Whilst this may represent a duplication of the target site of a maximum of $4 \mathrm{bp}$, further junctions 


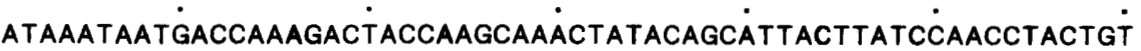
60 AAATTTATAG'TAGGTTTGTÁATTTAAAATÁTTAAAGTAAÄTTTACAAATÁACTCTTAAGT GAGATAGTCTAAATAAATGAATTGATGTGCACCCCAAAAG'TTAGACTTTTTTATCCAGGTA

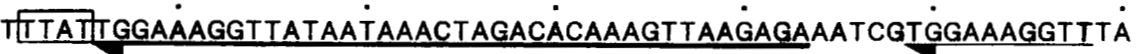

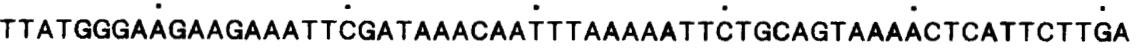

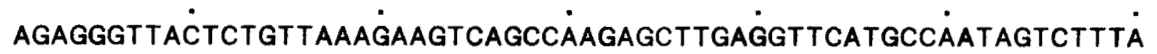

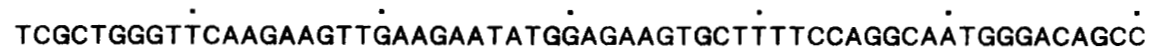

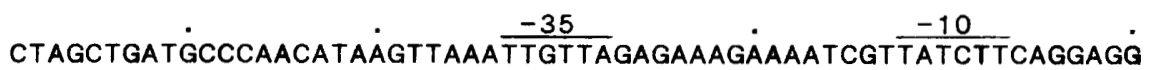

$\frac{-35}{\text { AACTTGAACTTCTAAAAAAGTTCCAGGTCTTCTTGAAGCGAAGCAAGTAAAACGTTTTGA }}$

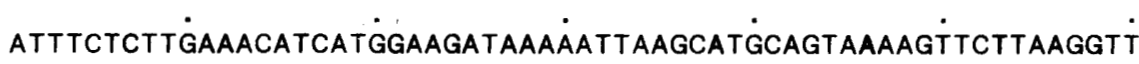

600

TCTCGCTCAGGTTTCTATGAATACATGCATCGTCGTCCTTCAAAACAACAAGTGGAGAGA

660

GAAATTCTCTCAGAGAAGA $\dot{T} A A A A G C T G T \dot{C} T T T C A T G A G \dot{C} A T A A G G G A C \dot{C} C T A T G G T G C \dot{~}$

E I L S E K I K $A$ A $V$ F

GTTAGAATTÁCCAAGGTACTICATAATACTंGGTATTATGÁCCAACACGAÄACGTGTTGGG

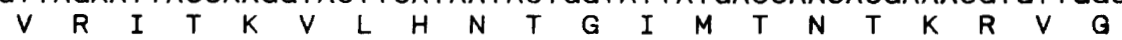

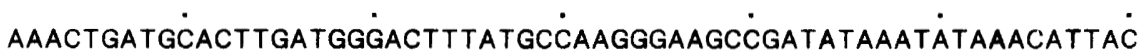
K L L M

AACAGAAAAGGAGCTTCGCTTTCAAGACCCAATTTAATTAATCAGATCTTंTAAAGCAACA

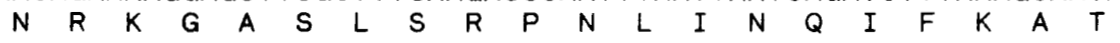

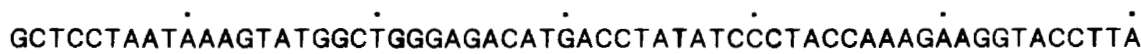

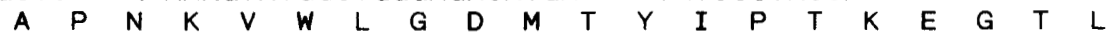
TACTTAGCCGTGAATATCGÁCGTTTTTTCÁंCGTAAGATTG'TAGGCTGGTCAATGTCTTCA $\begin{array}{llllllllllllllllllll}Y & L & A & V & N & I & D & V & F & S & R & K & I & V & G & W & S & M & S & S\end{array}$ CGGATGCAAGATAAACTGGTंGAGGGATTGC̈TTCTTACAAGCTTGTGGGAAAGAACATCC $\dot{T}$

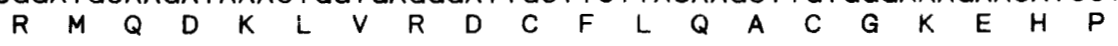

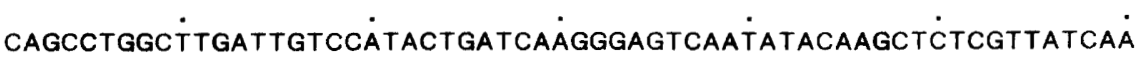
$\begin{array}{llllllllllllllllllll}Q & P & G & L & I & V & H & T & D & Q & G & S & Q & Y & T & S & S & R & Y & Q\end{array}$

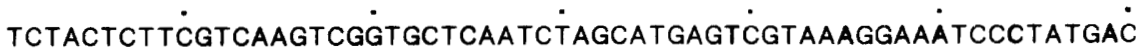
$\begin{array}{llllllllllllllllllll}S & T & L & R & Q & V & G & A & Q & S & S & M & S & R & K & G & N & P & Y & D\end{array}$ AATGCAATGAंTGGAGTCTTTTTTATAAGACGCTAAAGAGGGAGCTTATTAÁTGATGCTCA

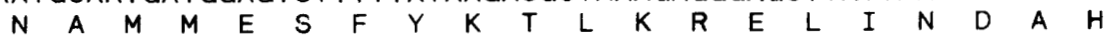

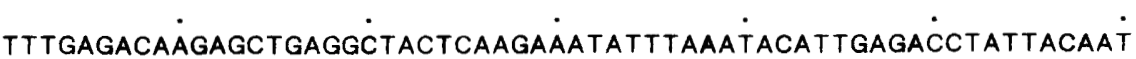

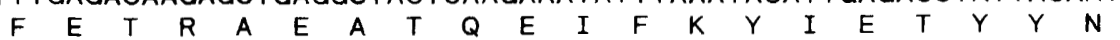
720 780 840 900 960 1020 1080 1140 1200 ACAAAAAGGAंTGCATTCAGG̈TCTTGATTACAAGTCTCCAÄAAGACTTTGÁAAAATATAA $\begin{array}{llllllllllllllllllll}T & K & R & M & H & S & G & L & D & Y & K & S & P & K & D & F & E & K & Y & N\end{array}$

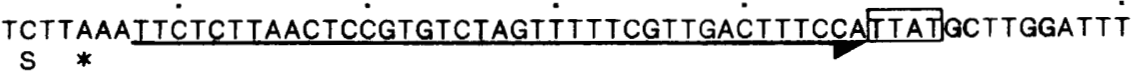




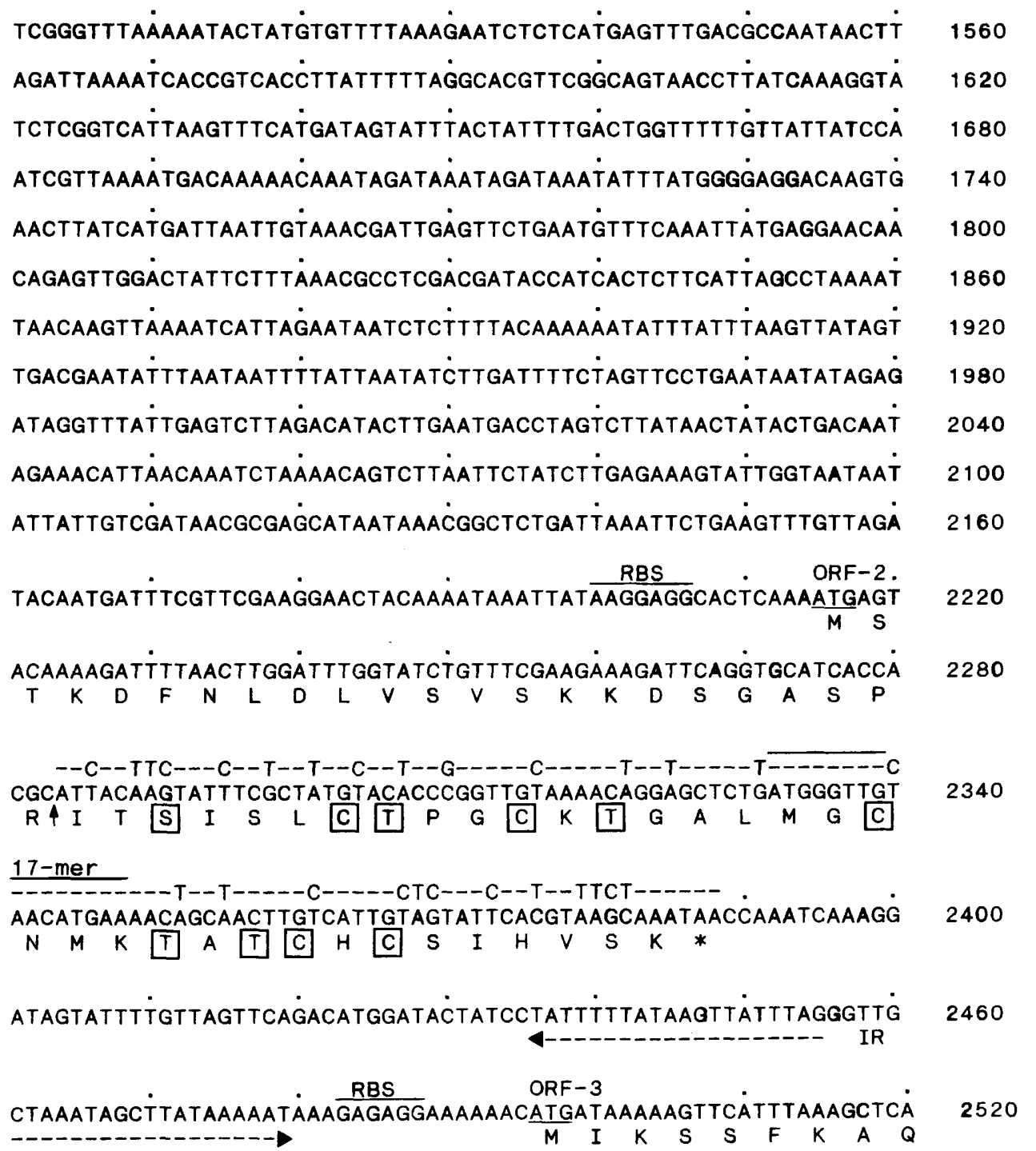

Fig. 3. Single-strand DNA sequence of the region of L. lactis FI5876 chromosome containing the precursor nisin structural gene. ORFs 1,2 (precursor nisin gene) and 3 are indicated, with the translation products given below the nucleotide sequence. The predicted sequence of the precursor nisin gene used as a probe is shown as a dashed line above the sequence (coordinates 2284 to 2388 ) with mismatches indicated. The solid line above nucleotides 2332 to 2348 shows the region corresponding to the mixed 17 -nucleotide oligomer used a primer. The arrow between the arginine and isoleucine residues (coordinate 2284) shows the point of cleavage of the $\mathrm{N}$ terminal leader sequence. Amino acids which contribute to lanthionine ring formation are boxed. RBS, ribosome-binding site. The horizontal dashed arrows below the sequence represent inverted repeat sequences which are potentially capable of forming stem-loop structures. One of these is located between the end of the precursor nisin gene and the start of ORF-3, and a second one is found upstream of ORF-1. Possible promoters for ORF-1 in this region are marked. The 39 bp inverted repeats (IR) which mark the termini of IS 904 (coordinates 186 to 1426) are indicated by solid lines below the sequence. The 4 bp duplicated sequences (TTAT) located at the two junctions are boxed.

resulting from insertion of this putative element into a region of known sequence would be necessary to establish the nature of the target site in the L. lactis genome.

Sequences upstream of the start of ORF-1 were analysed for potential transcriptional and translational start signals. No significant homology was found with the $3^{\prime}-\mathrm{OH}$ end of the 16S rRNA of $L$. lactis (Ludwig et al., 1985), which would be indicative of a ribosomebinding site. Two possible regions were located which shared some homology with the promoter consensus sequences proposed for Gram-positive bacteria (Graves 


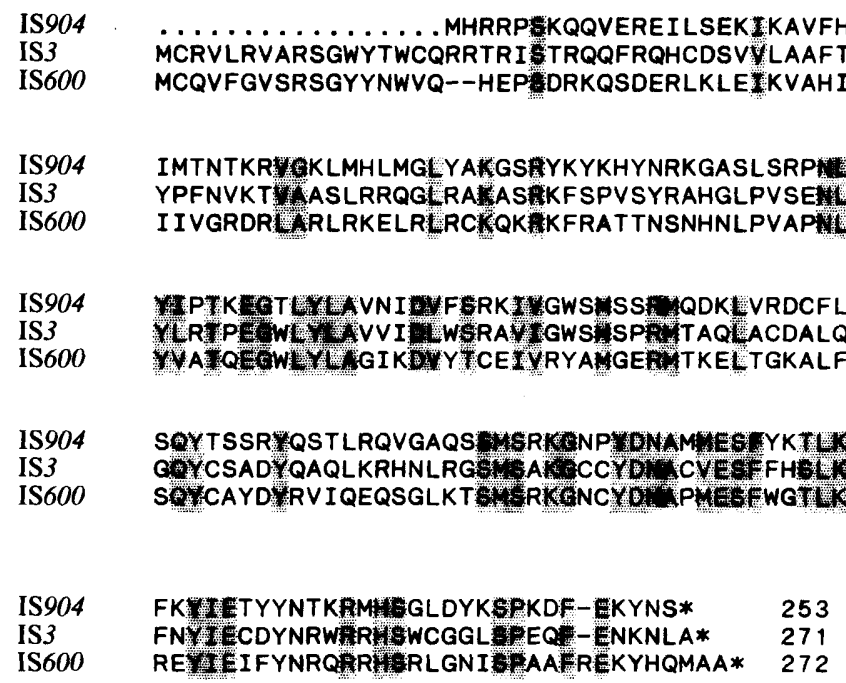

Fig. 4. Comparison of amino acid sequences of putative transposases encoded by IS 904, IS 3 and IS600. Amino acids which are the same or functionally equivalent in all three sequences are indicated by the shaded areas. (The conservative changes I, L, V and $M ; D$ and $\mathrm{E} ; \mathrm{Q}$ and $\mathrm{N} ; \mathrm{K}$ and $\mathrm{R} ; \mathrm{T}$ and $\mathrm{S} ; \mathrm{A}$ and $\mathrm{G} ; \mathrm{F}$ and $\mathrm{Y}$ are considered acceptable.) 'Padding', required to maximize homology, is indicated by dashes in the three sequences.

\begin{tabular}{|c|c|c|c|c|c|c|c|}
\hline \multicolumn{2}{|c|}{ Consensus } & \multicolumn{2}{|l|}{ TGR } & \multicolumn{2}{|l|}{ YRGA.AC } & \multicolumn{2}{|l|}{ YTAAG.GAR } \\
\hline IS904 & IR-L & TGG & AAAGGTTATAATAAAC & TAGACAC & AAAG & TTAAGAGAA & -- \\
\hline IS904 & IR-R & T'Ǵ & A'ÁÁG'CAÁCG'́AA'ÁÁÁC & 'TÁGÁCÁĆC & GGAG & 'T'TA'ÁA'GA'GÁÁ & -- \\
\hline IS3 & IR-L & TGA & TCTTACCCAGCAATAG & TGGACAC & GCGG & CTAAGTGAG & - \\
\hline IS3 & IR-R & TGA & TCCTACCCACGTAATA & TGGACAC & AGGC & CTAAGCGAG & -- \\
\hline IS600 & IR-L & TGA & GGTAGCCTGAGTTTAA & CGGACAC & TCC & & \\
\hline IS600 & IR-R & T'GA & GGTGTACTGGCAATAG & CGGÁCAĆ & TAC-- & & \\
\hline IS629 & IR-L & TGA & ACCGCCCCGGGAATCC & TGGAGAC & $T-$ & & \\
\hline IS629 & IR-R & T'GA & ACCGCCCCGGGTTTCC & T'GGAGAG & $T--$ & & \\
\hline
\end{tabular}

Fig. 5. Comparison of left (IR-L) and right (IR-R) inverted repeat sequences at the termini of IS 904 with other related elements. $5^{\prime}$ to $3^{\prime}$ single-stranded sequences are shown. Matches between the nucleotides of IR- $L$ and IR-R of each element are indicated by dashes. The consensus sequence is given above the eight termini; $\mathbf{R}=$ purine and $\mathbf{Y}=$ pyrimidine. Boxed regions indicate regions common to all the IRs.

\& Rabinowitz, 1986). One of these lies entirely within a region of dyad symmetry whilst the other coincides with one end of this repeated sequence (Fig. 3). The two complementary IRs could form a stem structure of $21 \mathrm{bp}$ with two mis-matches $\left(\Delta G^{\circ}=-19 \mathrm{kcal} \mathrm{mol}^{-1}\right.$; $-79.5 \mathrm{~kJ} \mathrm{~mol}^{-1}$ ). The role of similar secondary structures in regulation of transposition has been implicated for a number of other IS elements (see Timmerman \& Tu, 1985). A different arrangement of sequences exists for the elements IS 3 and IS600, in which a second small ORF, with appropriate transcription initiation sites, is located upstream of the transposase coding region. It has been suggested that expression of the transposase occurs as a result of transcription of a bicistronic mRNA (Timmerman \& Tu, 1985). The $L$. lactis IS904 sequences lying between IR-L and the start of ORF-1 bear no resemblance to those in the equivalent regions of IS 3 and IS 600 . The ability of IS 904 to transpose and the significance of the internal inverted and directly repeated sequences is at present unknown.

One of the properties of these discrete sequences is their ability to influence the level of expression of nearby 
genes (Saedler et al., 1974): Indeed, it has been demonstrated that IS3 can switch on a silent gene in $E$. coli (Zafarullah et al., 1981). The possibility exists that IS904 may be involved in expression of the downstream nisin determinants. An alternative explanation for this arrangement of sequences in $L$. lactis FI5876 may be simply the fortuitous insertion of IS904 at this site. However, partial sequence data of Buchman et al. (1988) indicate that this element is resident in a similar location in L. lactis ATCC 11454. It will be interesting to see whether this element is also present on the plasmid carrying the nisin determinant in L. lactis 6F3 (Kaletta \& Entian, 1989).

The homology between sequences of IS904 and those encoded by IS 3 and IS600 supports the idea that these elements have evolved from a common ancestor. There are other examples transposable elements traversing the barrier between Gram-negative and Gram-positive organisms. Tn917, isolated from Enterococcus faecalis (Perkins \& Youngman, 1984), is a member of a large class of antibiotic resistance transposons, the prototype of which is Tn3 from Escherichia coli (Heffron, 1983). The only other IS element to be described in $L$. lactis to date is ISSIS (Polzin \& Shimizu-Kadota, 1987), which also displays homology with IS elements located in both Gram-negative and other Gram-positive organisms (see Delecluse et al., 1989). The divergence of IS 904 from the other related elements would seem to have occurred a long time ago. Possible transcription initiation signals in IS904 show no similarity to those of IS3 and IS600, suggesting a difference between the respective hosts in the expression of IS-encoded genes. Furthermore, despite the similarity in the amino acid sequences of the putative transposases, the ORF in IS904 tends to follow codon usage characteristic of other $L$. lactis genes.

\section{Hybridization analysis}

The introduction of nisin genes by conjugal transfer into L. lactis MG1614 was investigated using DNA probes for the nisin structural gene (probe 3), for IS904 (probe 2) and for a region located on the opposite side of this element to the precursor nisin gene (probe 1; Fig. $6 b$ ). DNA from the nisin-producing strain FI5876 and the non-nisin-producing recipient strain MG1614 was digested with PvuII and with both PvuII and HindIII. Southern blots of the digestion patterns were hybridized with the three specific probes.

Probe 3 was generated by PCR using specific primers from within the precursor nisin gene. This 185 bp probe hybridized to an $8 \mathrm{~kb}$ PvuII fragment and a $4.3 \mathrm{~kb}$ PvuII/HindIII fragment of FI5876 (Fig. $6 a$, tracks 2 and 4). This same probe failed to give a signal with the

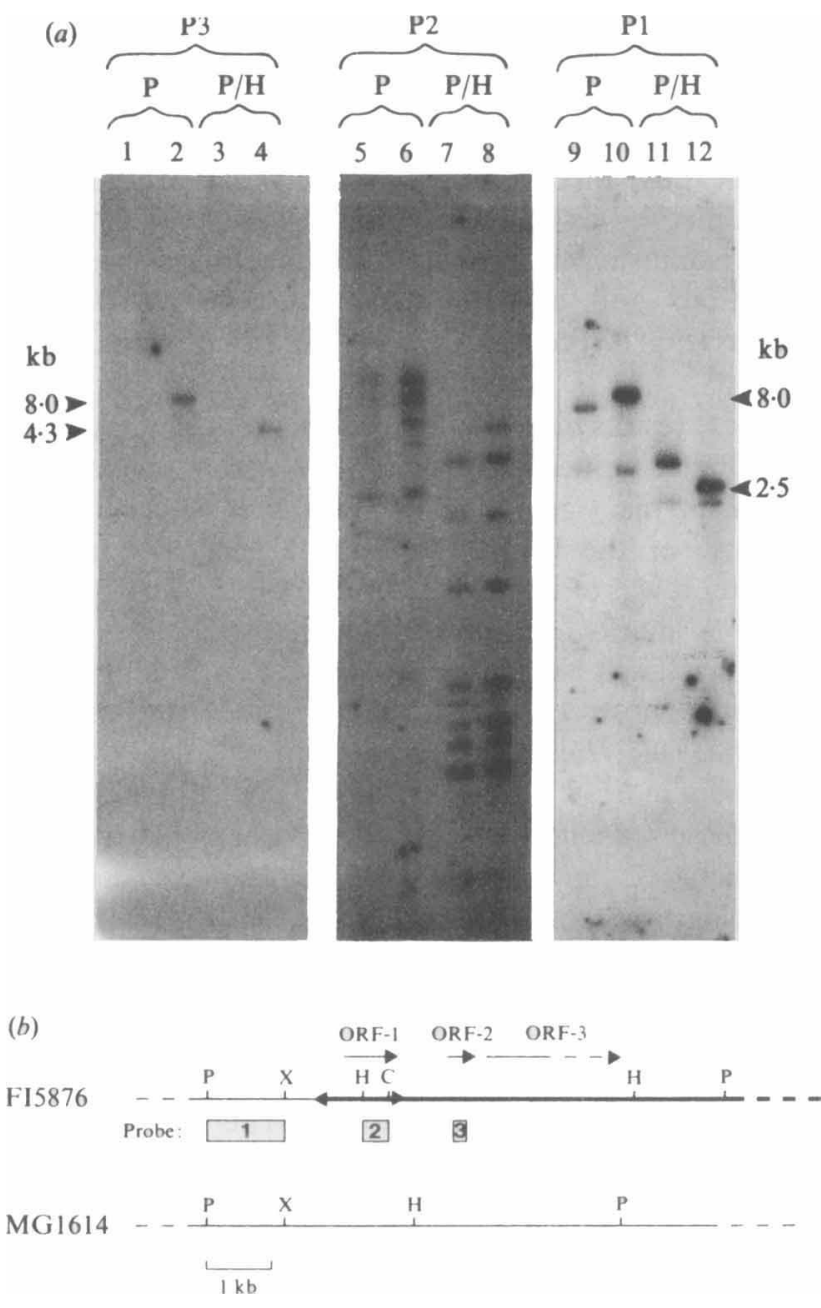

Fig. 6. (a) Hybridization patterns of L. lactis MG1614 and FI5876 chromosomal DNA digested with PvuII (P) and PvuII/HindIII (P/H). MG1614 digests are in the odd-numbered tracks and FI5876 digests are in the even-numbered tracks. P1, P2 and P3 refer to the ${ }^{32} \mathrm{P}$-labelled probes used in the three hybridizations, the numbers corresponding to the probes shown below the map of FI5876. (b) Maps of equivalent chromosomal regions of strains FI5876 and MG1614. Restriction enzyme sites are as above, plus X, $\mathrm{XbaI} ; \mathrm{C}, \mathrm{HincII}$. The thick line in the FI5876 map denotes DNA acquired as a result of transfer of the nisin/sucrose gene block to this strain. Arrows indicate the IRs of IS904. ORFs identified from the sequence are shown over the maps. The boxes under the F15876 map indicate the regions from which probes 1,2 and 3 were isolated.

MG1614 digests (Fig. 6a, tracks 1 and 3), indicating that the non-nisin-producing strain lacked the precursor nisin gene. FI5876 thus gained these sequences as a result of the conjugation event in which the nisin/sucrose gene block was transferred.

Probe 2 was derived from sequences within IS904 and was isolated as a HindIII/HincII restriction fragment (Fig. $6 b$ ). This probe hybridized to many bands in digests 
of both FI5876 and MG1614 DNA, indicating that this element was present in at least seven copies within the $L$. lactis MG1614 genome (Fig. 6a, tracks 5 and 7). An extra band was present in hybridizations with FI5876 and, significantly, the additional band, in both digests, was the same size as the band displaying homology to the precursor nisin gene probe, i.e. an $\mathbf{8 ~ k b}$ fragment in $P v u I I$ digestions and a $4.3 \mathrm{~kb}$ fragment in PvuII/HindIII digests (Fig. $6 a$ : compare tracks 6 and 2 and tracks 8 and 4).

These results indicated that the nisin-producing strain FI5876 had gained a segment of DNA that included the precursor nisin gene and the upstream copy of IS904. Because of the involvement of IS elements in gene transfer it was of interest to determine whether this copy of IS 904 marks one end of the gene block.

Probe 1 was isolated as a $\mathrm{PvuII} / \mathrm{XbaI}$ fragment from sequences upstream of IS 904 . This probe hybridized to a $2.5 \mathrm{~kb} \mathrm{PvuII/HindIII} \mathrm{fragment} \mathrm{and} \mathrm{to} \mathrm{an} 8 \mathrm{~kb} P v u \mathrm{II}$ fragment in FI5876 digests (Fig. 6a, track 10), indicating that these sequences lie within the same PvuII fragment as probes 2 and 3. MG1614 DNA also displayed homology to probe 1 , although the size of the hybridizing fragments differed from those in FI5876 digests (Fig. $6 a$, tracks 9 to 12). The $2.5 \mathrm{~kb} P v u I I / H i n d I I I$ fragment of FI5876, containing IR-R of IS904, is absent and is replaced by a larger band in the equivalent MG1614 digest (Fig. $6 a$, tracks 11 and 12). The absence of the IS904 junction band in the MG1614 digestions suggests that a copy of this element is not present in the equivalent region of the MG1614 chromosome. A second weak signal was evident after hybridization of these digestions with probe 1 (Fig. $6 a$, tracks 9 to 12). The additional bands were the same size for the two strains and there were no bands of equivalent size hybridizing to probe 2 (Fig. $6 a$, tracks 5 to 8 ). Thus, while a second region of the $L$. lactis chromosome displayed a lesser degree of homology with probe 1 , these sequences are not considered to be involved in the DNA rearrangements under investigation in this study.

The data obtained from Southern blot hybridization experiments are consistent with maps for the equivalent regions of FI5876 and MG1614 chromosomes as shown in Fig. 6(b). The involvement of IS904 in transfer of a chromosomal nisin/sucrose gene block is implicated by the conclusion that this element lies at, or very close to, the terminus of sequences acquired by nisin-producing transconjugants. IS elements have the ability to mobilize DNA sequences lying between two copies of the transposable sequences. Many examples of the evolution of these composite transposons in $E$. coli have been described (Berg et al., 1982; Kleckner, 1983; Iida et al., 1983). A similar arrangement of the sequences described here would result in the nisin/sucrose gene block being bounded by a copy of IS904 at each end. Transfer might then be achieved by a conservative transposition event, mediated by the transposase of IS904, in which the entire gene block is excised (see Berg et al., 1988). Alternatively, the two copies of IS904 may be substrates for homologous recombination, the outcome again being excision of the gene block from the chromosome in circular form. Conjugation functions mediating transfer between strains may be located within this hypothetical intermediate structure. This would be a similar arrangement to that found in the well-characterized streptococcal conjugative transposons, Tn916 and Tn919 (Franke \& Clewell, 1981; Clewell \& Gawron-Burke, 1986; Fitzgerald \& Clewell, 1985), in which a major segment of the element is devoted specifically to a conjugative function (Senghas et al., 1988). A chromosomally located transposable sex factor involved in directing highfrequency plasmid transfer in L. lactis has been described (Fitzgerald \& Gasson, 1988). The strains used in this study encode this independent conjugation function and it is possible that it, or other as yet uncharacterized conjugal systems, may be involved in transfer of the nisin/sucrose gene block. The various possibilities are being investigated.

The production of the peptide antibiotic nisin, together with the necessarily associated nisin resistance determinant, clearly puts these cells at a selective advantage over other susceptible cells in the same environment. IS-mediated events tend to occur at low frequency, but their activity has the effect of increasing the plasticity of the bacterial genome in their vicinity. The presence of IS 904 adjacent to the nisin determinants of $L$. lactis may provide a means by which these beneficial traits can evolve and spread throughout populations.

We wish to thank Dr W. C. Chan and Professor B. W. Bycroft of Nottingham University and Professor G. C. K. Roberts of Leicester University for helpful discussions.

\section{References}

Allgaier, H., Jung, G., Werner, R. G., Schneider, U. \& Zahner, H. (1986). Epidermin: sequencing of a heterodet tetracyclic 21peptide amide antibiotic. European Journal of Biochemistry 160, 9-22.

BANERJEe, S. \& HANSEN, J. N. (1988). Structure and expression of a gene encoding the precursor of subtilin, a small peptide antibiotic. Journal of Biological Chemistry 263, 9508-9514.

BenKerRoum, N. \& SANDINE, W. E. (1988). Inhibitory action of nisin against Listeria monocytogenes. Journal of Dairy Science 71, 32373245 .

Berg, D. E., JohnsRud, L., McDivitt, L., Ramabhadran,R. \& HiRSCHEL, B. J. (1982). Inverted repeats of Tn5 are transposable elements. Proceedings of the National Academy of Sciences of the United States of America 79, 2632-2635.

Berg, D. E., Kazic, T., Phadnis, S. H., Dodson, S. H. \& Lodge, J. K. (1988). Mechanism and regulation of transposition. In Transposition pp. 107-129. Edited by A. J. Kingsman, K. F. Chater \& S. M. Kingsman. Cambridge: Cambridge University Press. 
Buchman, W. B., Banerjee, S. \& Hansen, J. N. (1988). Structure, expression, and evolution of a gene encoding the precursor of nisin, a small protein antibiotic. Journal of Biological Chemistry 263, 1626016266.

Casadaban, M. J. \& Cohen, S. N. (1980). Analysis of gene control signals by DNA fusion and cloning in Escherichia coli. Journal of Molecular Biology 138, 179-207.

Clewell, D. B. \& Gawron-Burke, C. (1986). Conjugative transposons and the dissemination of antibiotic resistance in streptococci. Annual Review of Microbiology 40, 635-659.

Cohen, S. N., Chang, A. C. Y. \& Hsu, L. (1972). Nonchromosomal antibiotic resistance in bacteria: genetic transformation of Escherichia coli by R-factor DNA. Proceedings of the National Academy of Sciences of the United States of America 69, 2110-2114.

Delecluse, A. Bourgouin, C., Klier, A. \& Rapoport, G. (1989). Nucleotide sequence and characterization of a new insertion element IS240 from Bacillus thuringiensis israelensis. Plasmid 21, 71-78.

Fitzgerald, G. F. \& Clewell, D. B. (1985). A conjugative transposon (Tn919) in Streptococcus sanguis. Infection and Immunity $47,415-420$.

FitzGerald, G. F. \& Gasson, M. (1988). In vivo gene transfer systems and transposons. Biochimie 70, 489-502.

Franke, A. E. \& Clewell, D. B. (1981). Evidence for a chromosomeborne resistance transposon ( $\operatorname{Tn} 916)$ in Streptococcus faecalis that is capable of 'conjugal' transfer in the absence of a conjugative plasmid. Journal of Bacteriology 145, 494-502.

Fuchs, P. G., ZaJdel, J. \& DobrzansKi, W. T. (1975). Possible plasmid nature of the determinant for production of the antibiotic nisin in some strains of Streptococcus lactis. Journal of General Microbiology 88, 189-192.

Gasson, M. J. (1983). Plasmid components of Streptococcus lactis NCDO 712 and other lactic streptococci after protoplast-induced curing. Journal of Bacteriology 154, 1-9.

Gasson, M. J. (1984). Transfer of sucrose fermenting ability, nisin resistance and nisin production into Streptococcus lactis 712. FEMS Microbiology Letters 21, 7-10.

Gasson, M. J., Hill, S. H. \& Anderson, P. H. (1987). Molecular genetics of metabolic traits in lactic streptococci. In Streptococcal Genetics, pp. 242-245. Edited by J. Ferretti \& R. Curtiss III. Washington, DC: American Society for Microbiology.

Gonzalez, C. F. \& KunKa, B. S. (1985). Transfer of sucrose fermenting ability and nisin production phenotype among lactic streptococci. Applied and Environmental Microbiology 49, 627-633.

Graves, M. C. \& Rabinowitz, J. C. (1986). In vivo and in vitro transcription of the Clostridium pasteurianum ferredoxin gene. Journal of Biological Chemistry 261, 13744-13753.

Gross, E. \& KiLTZ, H. H. (1973). The number and nature of $\alpha, \beta$ unsaturated amino acids in subtilin. Biochemical and Biophysical Research Communications 50, 559-565.

Gross, E. \& Morell, J. (1971). The structure of nisin. Journal of the American Chemical Society 93, 4634-4635.

HefrRon, F. (1983). Tn3 and its relatives. In Mobile Genetic Elements, pp. 223-260. Edited by J. A. Shapiro. New York: Academic Press.

Humphreys, G. O., Weston, A., Brown, M. G. M. \& Saunders, J. T. (1979). In Transformation - 1978, pp. 254-279. Edited by S. W. Glover \& L. O. Butler. Oxford: Cotswold Press.

HURST, A. (1981). Nisin. Advances in Applied Microbiology 27, 85-123.

IIDA, S., MeYer, J. \& ARber, W. (1983). Prokaryotic IS elements. In Mobile Genetic Elements, pp. 159-221. Edited by J. A. Shapiro. New York: Academic Press.

INGRAM, A. (1970). A ribosomal mechanism for synthesis of peptides related to nisin. Biochimica et Biophysica Acta 224, 263-265.

Kaletta, C. \& Entian, K.-D. (1989). Nisin, a peptide antibiotic: cloning and sequencing of the nis $\mathrm{A}$ gene and post-translational processing of its peptide product. Journal of Bacteriology 171, 15971601 .

Kellner, R., Jung, G., Horner, T., Zahner, H., Schnell, N., ENTIAN, K.-D. \& GoTZ, F. (1988). Gallidermin, a new lanthionine containing polypeptide antibiotic. European Journal of Biochemistry 177, 53-59.

KlaENHAMmER, T. R. (1988). Bacteriocins of lactic acid bacteria. Biochimie 70, 337-349.
KLECKNER, N. (1983). Transposon Tn10. In Mobile Genetic Elements, pp. 261-298. Edited by J. A. Shapiro. New York: Academic Press.

KozAK, W., RAJChERT-TrzPIL, M. \& Dobrzanski, W. T. (1974). The effect of proflavin, ethidium bromide and an elevated temperature on the appearance of nisin-negative clones in nisin-producing strains of Steptococcus lactis. Journal of General Microbiology 83, 295-302.

Leblanc, D. J., Crow, V. L. \& LeE, L. N. (1980). Plasmid mediated carbohydrate catabolic enzymes among strains of Streptococcus lactis. In Plasmids and Transposons: Environmental Effects and Maintenance Mechanisms, pp. 31-41. Edited by C. Stuttard \& K. R. Rozee. New York: Academic Press.

LeDerberg, E. M. (1987). Plasmid reference center registry of transposon ( $\mathrm{Tn}$ ) and insertion sequence (IS) allocations through December, 1986. Gene 51, 115-118.

LENNOX, E. S. (1955). Transduction of linked genetic characters of the host bacteriophage P1. Virology 1, 190-206.

Lewington, J., Greenaway, S. D. \& Spillane, B. J. (1987). Rapid small scale preparation of bacterial genome DNA suitable for cloning and hybridization analysis. Letters in Applied Microbiology 5 , $51-53$.

Ludwig, W., Seewaldt, E., Kilpper-Balz, R., Schleifer, K. H., Magrum, L., Woese, C. R., FoX, G. E. \& Stackebrandt, E. (1985). The phylogenic position of Streptococcus and Enterococcus. Journal of General Microbiology 131, 543-551.

Maniatis, T., Fritsch, E. F. \& Sambrook, J. (1982). Molecular Cloning: a Laboratory Manual. Cold Spring Harbor, NY: Cold Spring Harbor Laboratory.

Matsutani, S., Ohtsubo, H., Maeda, Y. \& Ohtsubo, E. (1987). Isolation and characterization of IS elements repeated in the bacterial chromosome. Journal of Molecular Biology 196, 445-455.

MCKAY, L. L., Baldwin, K. A. \& ZotTola, E. A. (1972). Loss of lactose metabolism in lactic streptococci. Applied and Environmental Microbiology 23, 1090-1096.

Perkins, J. B. \& Youngman, P. J. (1984). A physical and functional analysis of $\operatorname{Tn} 917$, a Streptococcus transposon in the $\operatorname{Tn} 3$ family that functions in Bacillus. Plasmid 12, 119-138.

Polzin, K. M. \& Shimizu-Kadota, M. (1987). Indentification of a new insertion element, similar to gram-negative IS26, on the lactose plasmid of Streptococcus lactis ML3. Journal of Bacteriology 169, 5481-5488.

ROSENBERG, M. \& COURT, D. (1979). Regulatory sequences involved in the promotion and termination of RNA transcription. Annual Review of Genetics 13, 319-353.

SAEDLER, H., ReIF, H. J., Hu, S. \& Davidson, N. (1974). IS2, a genetic element for turn-off and turn-on of gene activity in E. coli. Molecular and General Genetics 132, 265-289.

Sanger, F., Coulson, A. R., Barrell, B. G., Smith, A. J. H. \& ROE, B. A. (1980). Cloning in single-stranded bacteriophage as an aid to rapid DNA sequencing. Journal of Molecular Biology 143, $161-178$.

SChNell, N., ENTIAN, K.-D., SChNeider, U., Gotz, F., ZahNer, H., Kellner, R. \& JUnG, G. (1988). Prepeptide sequence of epidermin, a ribosomally synthesized antibiotic with four sulphide rings. Nature, London 333, 276-278.

SChNell, N., ENTIAN, K.-D., Gotz, F., Horner, T., Kellner, R. \& JUNG, G. (1989). Structural gene isolation and prepeptide sequence of gallidermin, a new lanthionine containing antibiotic. FEMS Microbiology Letters 58, 263-268.

Senghas, E., Jones, J. M., Yamamoto, M., Gawron-Burke, C. \& Clewell, D. B. (1988). Genetic organization of the bacterial conjugative transposon Tn916. Journal of Bacteriology 170, 245-249.

Shearman, C. A., Underwood, H., JuRY, K. \& Gasson, M. (1989). Cloning and DNA sequence analysis of a Lactococcus bacteriophage lysin gene. Molecular and General Genetics 218, 214-221.

STEELE, J. L. \& MCKAY, L. L. (1986). Partial characterization of the genetic basis for sucrose metabolism and nisin production in Streptococcus lactis. Applied and Environmental Microbiology 51, 5764.

TAYLOR, S. M. \& SOMERS, E. B. (1985). Evaluation of the antibotulinal effectiveness of nisin in bacon. Journal of Food Protection 48, 949952. 
TERZAGHI, B. E. \& SANDINE, W. E. (1975). Improved medium for lactic streptococci and their bacteriophages. Applied Microbiology 29, 807813.

TIMmERMAN, K. P. \& TU; C.-P. D. (1985). Complete sequence of IS3. Nucleic Acids Research 13, 2127-2139.

Tramer, J. \& Fowler, G. G. (1964). Estimation of nisin in foods Journal of the Science of Food and Agriculture 15, 522-528.

TSAI, H.-J. \& SANDINE, W. E. (1987). Conjugal transfer of nisin plasmid genes from Streptococcus lactis 7962 to Leuconostoc dextranicum 181 Applied and Environmental Microbiology 53, 352-357.
Yoshioka, Y., OHtsubo, H. \& OHtsubo, E. (1987). Repressor gene finO in plasmids $\mathrm{R} 100$ and $\mathrm{F}$ : constitutive transfer of plasmid $\mathrm{F}$ is caused by insertion of IS3 into $\mathrm{F}$ finO. Journal of Bacteriology 169. 619-623.

Zafarullah, M., Charlier, D. \& Glansdorff, N. (1981). Insertion of IS3 can 'turn-on' a silent gene in Escherichia coli. Journal of Bacteriology 146, 415-417. 